\title{
Planejamento e implementação de uma proposta de estudos para a Geometria na perspectiva do Enfoque Ontosemiótico
}

\author{
Andrielly Viana Lemos \\ Carmen Teresa Kaiber
}

\begin{abstract}
Resumo: Este artigo tem como objetivo apresentar um recorte dos resultados de uma investigação que tomou como referência as ferramentas do Enfoque Ontosemiótico (EOS) para o desenvolvimento e implementação de uma proposta de estudos de recuperação para a Geometria dos anos finais do Ensino Fundamental. A investigação, de base qualitativa, foi realizada com estudantes do $9^{\circ}$ ano de uma Escola Municipal de São Leopoldo/RS. Serão apresentadas reflexões e análises produzidas sobre o material de estudos Figuras Geométricas. Os resultados apontaram que as dimensões interacional, emocional e mediacional, em grande parte dos seus componentes e indicadores, atingiram um grau alto de idoneidade. Porém, com relação argumentação, relações e síntese, tanto no que se refere ao material produzido como também nos significados atribuídos pelos estudantes, esse grau de idoneidade se revelou médio.
\end{abstract}

Palavras-chave: Enfoque Ontosemiótico. Idoneidade Didática. Geometria. Figuras Geométricas. Ensino Fundamental.

Andrielly Viana Lemos Doutorado em Ensino de Ciências e Matemática pela Universidade Luterana dp Brasil, campus Canoas. Professora Tutora da Universidade Luterana do Brasil (ULBRA), Canoas, RS, Brasil. https://orcid.org/0000-0002-0871-525X \ andriellylemos@gmail.com

Carmen Teresa Kaiber Doutorado em Ciências da Educação pela Universidade Pontifícia de Salamanca, Espanha. Professora da Universidade Luterana do Brasil (ULBRA), Canoas, RS, Brasil.

http://orcid.org/0000-0003-1883-230X ه carmen.kaiber@ulbra.br

Recebido em 30/06/2021 Aceito em 21/08/2021 Publicado em 09/09/2021

\section{Planning and implementation of a study proposal for Geometry from the perspective of the Ontosemiotic Approach}

Abstract: This article presents an excerpt of the results of an investigation that took as reference the tools of the Ontosemiotic Approach (OSA), aimed at developing and implementing a proposal for reinforcement studies on geometry in the final years of elementary school. The qualitative-based investigation was carried out with 9 th -grade students from a municipal school in São Leopoldo/RS, Brazil. Reflections and analyses produced on the study material of geometric figures will be presented. The results showed that the interactional, emotional, and mediational dimensions, in most oftheir components and indicators, reached a high degree of suitability. However, about argumentation, relationships, and synthesis, both regarding the material produced and the meanings attributed by the students, this degree of suitability proved to be medium.

Keywords: Ontosemiotic approach. Didactic suitability. Geometry. Geometric Figures. Elementary School.

\section{Planificación e implementación de una propuesta de estudio para la Geometría desde la perspectiva del Enfoque Ontosemiótico}

\begin{abstract}
Resumen: Este artículo presenta un recorte de los resultados de una investigación que tomó como referencia las herramientas del Enfoque Ontosemiótico (EOS), con el objetivo de desarrollar e implementar una propuesta de estudios de refuerzo en geometría en los primeros años de secundaria. La investigación de base cualitativa se llevó a cabo con estudiantes de noveno grado de una escuela municipal en São Leopoldo/RS, Brasil. Se presentarán reflexiones y análisis producidos sobre el material de estudio de figuras geométricas. Los resultados mostraron que las dimensiones interaccional, emocional y mediacional, en la mayoría de sus componentes e indicadores, alcanzaron un alto grado de idoneidad. Sin embargo, en la argumentación, las relaciones y la síntesis, tanto en el material producido como en los significados atribuidos por los estudiantes, este grado de idoneidad resultó ser medio.
\end{abstract}

Palabras clave: Enfoque Ontosemiótico. Idoneidad didáctica. Geometría. Figuras Geometricas. Liceo. 


\section{Introdução}

O ambiente escolar é múltiplo e heterogêneo e nele convivem estudantes com competências, habilidades, interesses, motivações e tempos de aprendizagem distintos. Assim, nem todos os estudantes conseguem desenvolver os conhecimentos e habilidades necessários para uma aprendizagem satisfatória, nas condições e tempo estabelecidos, o que remete à necessidade de que sejam promovidos espaços, condições e meios para que a aprendizagem possa se desenvolver satisfatoriamente incluindo-se aí a possibilidade de estudos de recuperação, visando uma retomada, ressignificação e ampliação dos conhecimentos.

Neste contexto, as discussões em torno do desenvolvimento de propostas de estudos de recuperação retomam sua posição como um elemento necessário e importante dentro do processo de ensino e aprendizagem. Particularmente, no que diz respeito à aprendizagem em Matemática, a frequência com que os estudantes apresentam baixo desempenho e rendimento remete a necessidade de se organizar propostas que permitam uma retomada de conceitos, definições, propriedades e procedimentos que, em um primeiro momento, não foram aprendidos como o esperado (LEMOS; KAIBER, 2017).

Assim, a partir da necessidade e pertinência de se promover estudos de recuperação, o estudo aqui apresentado diz respeito a uma pesquisa que teve por objetivo investigar o desenvolvimento e implementação de uma proposta de estudos de recuperação em torno da Geometria, para os anos finais do Ensino Fundamental, sob a perspectiva do Enfoque Ontosemiótico do Conhecimento e a Instrução Matemática (EOS).

Encontrou-se no EOS o aporte para a investigação desenvolvida, tendo em vista que este enfoque contempla discussões tanto em torno do conhecimento matemático, como também, aspectos cognitivos, mediacionais, interacionais e emocionais envolvidos no processo de ensino e aprendizagem da Matemática, os quais permitem um olhar e uma ação sistêmica sobre esse processo. Já a escolha da Geometria como temática da proposta de estudos esteve relacionada, em um primeiro momento, ao fato de que a mesma tem sido foco de investigações e discussões não só no que se refere ao processo de ensino e aprendizagem, mas também, sobre sua possível ausência nas salas de aula da Educação Básica (PAVANELLO,1993; LORENZATO,1995; ANDRADE, 2004), constituindo-se em uma área da Matemática fragilizada na escola.

A investigação, de base qualitativa, seguiu os pressupostos da Investigação Baseada no Design - IBD (GODINO et al., 2013) e, além da organização dos materiais de estudos como descrito, envolveu 
a sua aplicação junto a um grupo de 15 estudantes do $9^{\circ}$ ano do Ensino Fundamental de uma escola pública do Município de São Leopoldo/RS. Os participantes foram indicados pela professora de matemática da escola, sendo que, o critério utilizado pela mesma foi selecionar os estudantes que apresentavam dificuldades com o estudo da Geometria e aceitaram participar da investigação. $O$ trabalho se desenvolveu em 40 horas aula, em turno inverso às aulas regulares dos estudantes.

Assim, no que segue, será apresentada e discutida a proposta de estudo de recuperação desenvolvida e como as ferramentas de análise do EOS foram utilizadas. Destaca-se que a proposta de estudos, e os resultados apresentados, são parte da tese de doutorado apresentada em Lemos (2017). Neste artigo, serão destacados resultados em torno do planejamento, implementação e análise do material de estudos referente as Figuras Geométricas.

\section{Estudos de recuperação para a Geometria: uma proposta para os anos finais do Ensino}

\section{Fundamental}

Pondera-se que os estudos de recuperação devem ser pensados e organizados considerando estratégias distintas das já utilizadas em sala de aula, visando oportunizar aos estudantes a vivência de situações e ações que retomem, sob outras perspectivas, caminhos já trilhados. Tendo em vista que se entende a recuperação como ato ou efeito de recuperar, retomar o que não foi plenamente consolidado com relação à apropriação de conceitos e procedimentos, a recuperação é assumida, aqui, como parte do processo de ensino e aprendizagem, não se constituindo em momento isolado, que ocorre por meio da aplicação de uma avaliação que objetiva somente recuperar uma nota, por exemplo (LEMOS, 2017).

A proposta de estudos de recuperação desenvolvida, e que tem como foco os conhecimentos geométricos dos anos finais do Ensino Fundamental, foi organizada contemplando quinze materiais de estudos, os quais foram planejados levando em consideração os significados institucionais, estabelecidos nos documentos oficiais para o ensino da Geometria, pesquisas na área (BRASIL, 1998; 2018; CRESCENTI, 2005; PIRES, 2000, ANDRADE, 2004) e os pressupostos do EOS, mais especificamente na Idoneidade Didática (GODINO, 2011; 2012; GODINO; BATANERO; FONT, 2008; ANDRADE, 2014).

Os materiais de estudos foram construídos em Power Point, articulando o desenvolvimento de conceitos, procedimentos e definições com situações problemas, atividades e jogos online, objetos de aprendizagem, uso de software, vídeos, bem como atividades de construção e manipulação. Têm como foco os principais tópicos referentes à Geometria dos anos finais do Ensino Fundamental: Figuras Geométricas; Ponto, Reta e Plano; Polígonos; Simetria; Ângulos; Triângulos; Quadriláteros; Área e 


\section{revemop}

Perímetro; Volume; Congruência; Semelhança, Teorema de Tales; Teorema de Pitágoras; Relações Métricas; Círculo e Circunferência. No que segue, se ilustra como estão estruturados os materiais de estudos.

Os tópicos desenvolvidos nos materiais estão estruturados a partir de uma introdução, seguida do desenvolvimento e a retomada dos conceitos e procedimentos referente ao tópico trabalhado e, por fim, se propõe uma síntese do que foi abordado no material. Entende-se que, com esta articulação, o estudo contempla o conhecimento teórico do objeto matemático, como também, são apresentadas atividades que encaminhem para a aplicação destes conhecimentos em situações-problema, podendo estas serem de contextualização, exercícios, construção ou explicações e justificativas (presentes no próprio material), na utilização de software, objetos de aprendizagem ou por meio de atividades online. Visando ilustrar como e aplicado junto aos estudantes, no que se refere aos materiais de estudo foram estruturados, apresentam-se, na Figura 1, partes do material sobre Figuras Geométricas.

Figura 1: Exemplo da introdução, desenvolvimento e finalização de um material de estudo

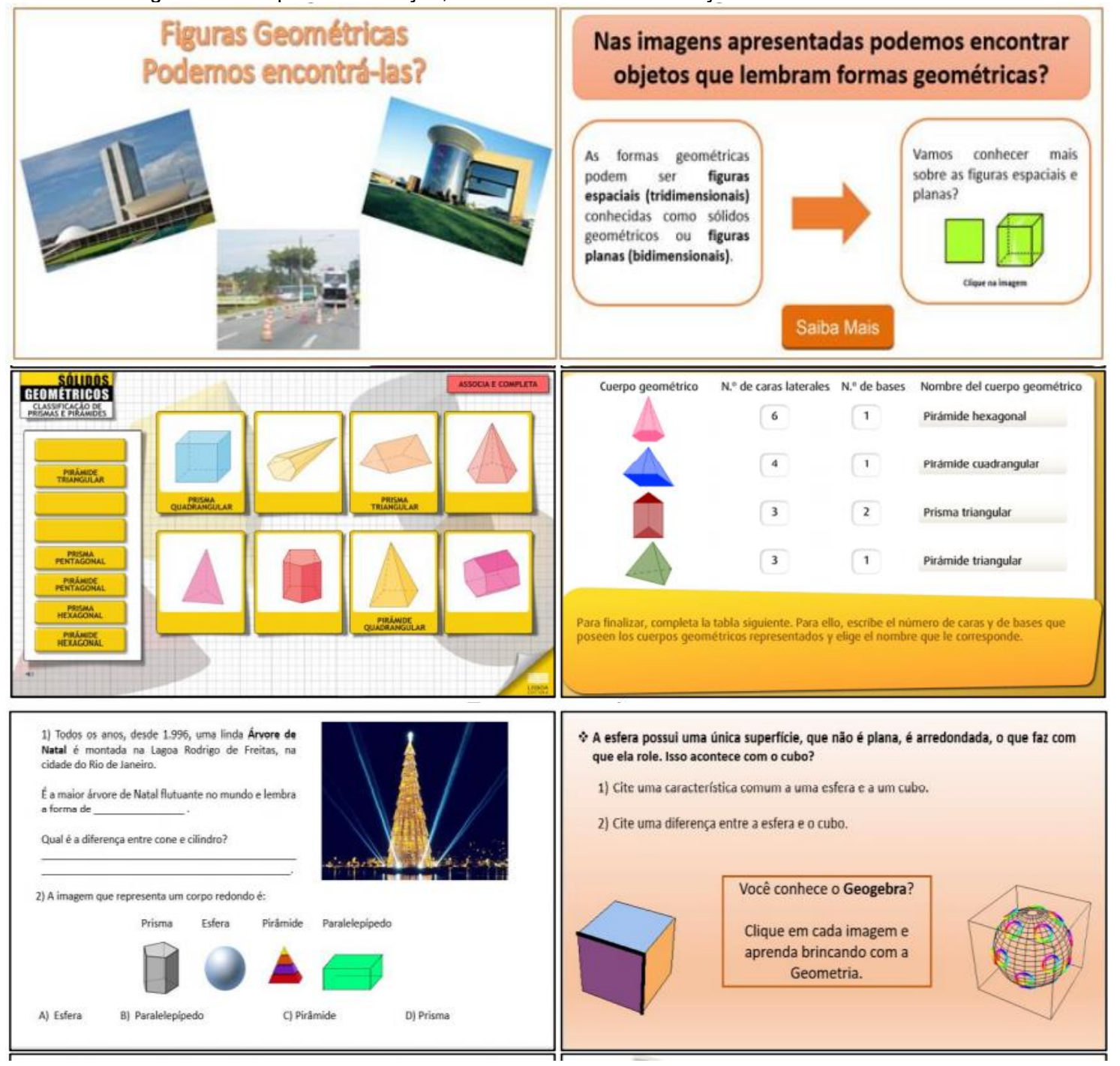




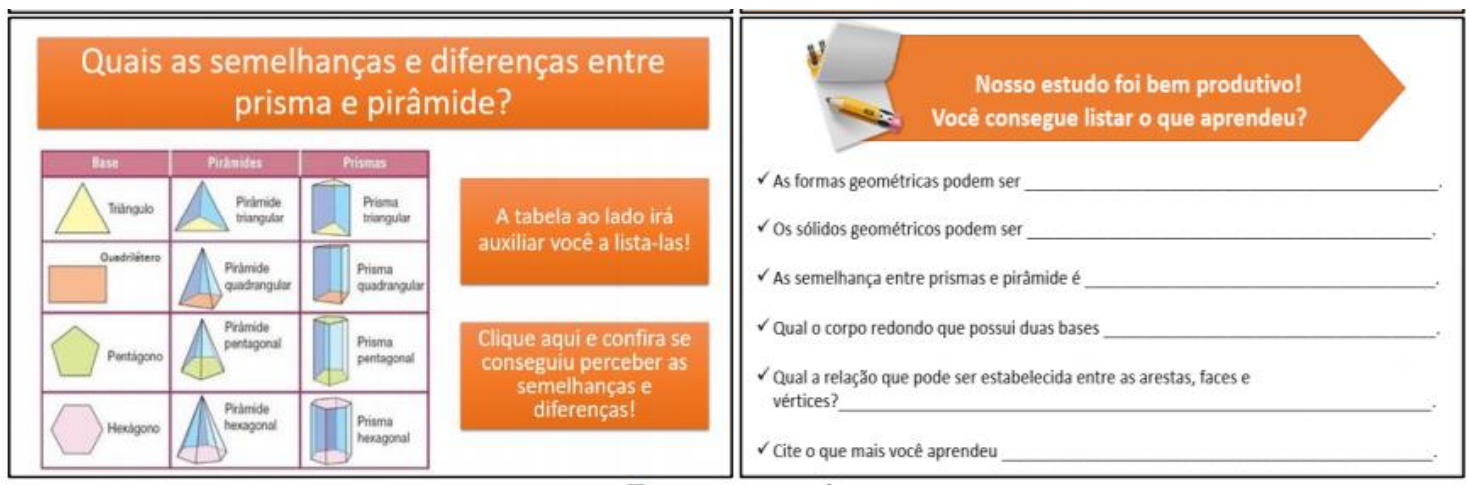

Fonte: adaptado de Lemos (2017).

Nas telas da Figura 1 são destacadas partes do material sobre as Figuras Geométricas onde, incialmente, são apresentadas imagens e os estudantes são instigados a relacioná-las com formas geométricas para, em seguida, retomar conceitos referentes a figuras espaciais e planas. Apresentamse também, atividades a fim de que os estudantes possam retomar os conceitos trabalhados e, por fim, propõe-se que seja realizada uma sistematização, visando que os estudantes reflitam e argumentem sobre o que foi estudado no material.

As ferramentas de análise do Enfoque Ontosemiótico que foram utilizadas no planejamento e implementação da proposta de estudos de recuperação são apresentadas e analisadas a seguir.

\section{Enfoque Ontosemiótico na constituição e implementação de uma proposta de estudos de recuperação: uma análise}

Os constructos do Enfoque Ontosemiótico (EOS), ao se voltarem para o conteúdo do conhecimento, para o ambiente escolar, para as ações e interações do professor e para o pensamento do estudante, permitem lançar um olhar para o processo educativo considerando uma multiplicidade de elementos que, articulados potencializam as práticas educativas. Essa multiplicidade possibilita não mais se olhar para o conteúdo ou para o método, para o professor ou para o aluno, para o ensino ou para a aprendizagem, isoladamente, ou em dicotomias que se alternavam no interesse de professores e pesquisadores (GODINO; BATANERO; FONT, 2008; GODINO et al., 2021).

Segundo Godino (2012), o conjunto de noções teóricas que compõem EOS estão articulados em cinco grupos: Sistemas de Práticas, Configurações de Objetos e Processos Matemáticos, Configurações e Trajetórias Didáticas, Dimensão Normativa e Idoneidade Didática. Cada um destes grupos, permite um nível de análise do processo de ensino e aprendizagem de tópicos específicos, objetivando descrever, explicar e avaliar as interações e práticas educativas presentes nas salas de aula de Matemática. 0 quinto nível de análise proposto, a Idoneidade Didática, que foi tomado como referência no trabalho 
desenvolvido, baseia-se nos outros quatro níveis e constitui-se em uma síntese final orientada a identificação de potenciais melhoras do processo de estudo em novas implementações.

Considerando a necessidade de estabelecer e investigar critérios que possam qualificar e tornar o processo mais adequado ou idôneo, a Idoneidade Didática pode ser utilizada como ferramenta de análise e reflexão, fornecendo critérios gerais de pertinência e relevância das ações dos educadores, do conhecimento posto em jogo, dos recursos utilizados, dos significados atribuídos pelos estudantes, a partir da articulação coerente e sistêmica de seis dimensões: idoneidade epistêmica, cognitiva, interacional, mediacional, emocional e ecológica (GODINO, 2011; GODINO, 2021 ), as quais pode ser atribuído um grau de idoneidade ou adequação (alto, médio ou baixo). No Quadro 1 apresentam-se os principais aspectos relacionados a essas seis dimensões.

Quadro 1 : Síntese das dimensões da Idoneidade Didática

\begin{tabular}{|c|l|}
\hline Idoneidade & \multicolumn{1}{c|}{ Síntese } \\
\hline Epistêmica & $\begin{array}{l}\text { Se refere ao grau de representatividade dos significados institucionais implementados, ou } \\
\text { pretendidos, com relação a um significado de referência. }\end{array}$ \\
\hline Cognitiva & $\begin{array}{l}\text { Focada no grau em que os significados pretendidos/implementados estão na área de } \\
\text { desenvolvimento potencial dos alunos, assim como, o grau de proximidade entre os significados } \\
\text { pessoais atingidos e os significados pretendidos/implementados }\end{array}$ \\
\hline Interacional & $\begin{array}{l}\text { Um processo de ensino e aprendizagem terá maior idoneidade, quando as configurações e } \\
\text { trajetórias didáticas implementadas permitem identificar conflitos semióticos potenciais bem como } \\
\text { resolver os conflitos que são produzidos durante o processo de ensino. }\end{array}$ \\
\hline Mediacional & $\begin{array}{l}\text { Refere-se ao grau de disponibilidade e adequação dos recursos materiais e temporais } \\
\text { necessários para o desenvolvimento do processo de ensino e aprendizagem. }\end{array}$ \\
\hline Emocional & $\begin{array}{l}\text { Contempla o grau de envolvimento dos alunos no processo de ensino. Esta dimensão está } \\
\text { relacionada com fatores que dependem tanto da instituição como do aluno e da sua história } \\
\text { escolar prévia. }\end{array}$ \\
\hline Ecológica & $\begin{array}{l}\text { Se refere ao grau em que o processo de estudo se ajusta ao projeto educacional, a escola, a } \\
\text { sociedade e ao ambiente em que se desenvolve }\end{array}$ \\
\hline
\end{tabular}
Fonte: adaptado de Godino, Batanero e Font (2008).

As dimensões destacadas no quadro da Figura 2, foram tomadas como critérios de análise para o desenvolvimento e implementação da proposta de estudos, bem como, os trabalhos de Godino, Rivas e Arteaga (2012), Godino et al. (2006) e Andrade (2014). Foi lançado um olhar para a proposta por meio das dimensões da Idoneidade Didática (epistêmica, cognitiva, interacional, mediacional, emocional e ecológica), buscando evidenciar os graus de idoneidade alcançados com os tópicos em estudo, em cada uma das dimensões. Os componentes e indicadores de cada uma das dimensões da Idoneidade Didática foram organizadas em torno do que foi denominado por Andrade (2014) de "Ferramentas de Análise".

Assim, com a análise epistêmica foi avaliado o material produzido para cada tópico da proposta, considerando os componentes e indicadores da Ferramenta de Análise Epistêmica - FAE, sendo eles: situações-problemas, linguagem, regras, argumentos e relações, buscando identificar o grau de idoneidade, considerando os significados institucionais estabelecidos. 
A dimensão cognitiva teve sua análise focada nos significados pretendidos com o material frente aos significados declarados pelos estudantes no processo de estudo, levando em consideração tanto os componentes e indicadores propostos pela Ferramenta de Análise Cognitiva - FAC (raciocínio lógico, leitura/interpretação e análise/síntese), como também, os epistêmicos.

Já a dimensão mediacional foi contemplada nas análises dos materiais de estudos considerando os recursos utilizados frente aos componentes e indicadores da Ferramenta de Análise de Mediacional - FAM, sendo eles: recursos e tempo didático. Considerando que a proposta de estudo tem como base 0 conjunto de materiais produzidos, esta análise permite verificar as potencialidades e as fragilidades encontradas nos materiais de estudos embora os mesmos, já na sua concepção, tenham sido elaborados considerando os aportes do EOS. Pondera-se que, é quando os estudantes atuam sobre materiais didáticos é que estes revelam suas potencialidades.

$\mathrm{Na}$ dimensão interacional foram analisadas as interações dos estudantes entre eles, com a pesquisadora e com o material, considerando os componentes e indicadores da Ferramenta de Análise Interacional - FAl, sendo eles: diálogo/comunicação, interação e autonomia. Tais interações foram registradas por meio de gravações em áudio e vídeo e das observações da pesquisadora, objetivando refletir sobre o grau de idoneidade das interações produzidas ao longo do desenvolvimento do trabalho.

A dimensão emocional teve um olhar para as questões atitudinais dos estudantes frente ao trabalho desenvolvido, por meio dos componentes e indicadores da Ferramenta de Análise Emocional FAEMO: motivação/interesse, envolvimento e crenças/atitudes. Os principais instrumentos de coleta de dados para esta análise foram os registros em áudio e vídeo e as observações da pesquisadora durante os encontros.

Na dimensão ecológica novamente a análise está voltada para o material produzido, no que se refere, a sua adequação aos significados institucionais de referência, ou seja, o que está posto nos documentos oficiais a nível internacional, nacional e regional e, também, o que é preconizado na escola para o desenvolvimento dos conhecimentos geométricos nos anos finais do Ensino Fundamental. Para esta análise foram considerados os componentes e indicadores da Ferramenta de Análise Ecológica FAECO: currículo, escola e sociedade.

Cabe ressaltar que foi realizada uma análise individual para cada um dos tópicos (temas) propostos para estudo no que se refere as dimensões Epistêmica, Cognitiva e Mediacional, tendo em vista, que estas dimensões apresentam especificidades em cada um deles, relevantes a serem discutidas individualmente. Já para as dimensões Interacional, Emocional e Ecológica foi realizada uma análise geral de toda a proposta, contemplando todos os tópicos em uma única análise, uma vez que as 
evidências percebidas nestas dimensões são semelhantes em todos os tópicos da proposta. Uma síntese de como a análise foi conduzida é apresentada na Figura 2.

Figura 2: Estrutura da análise: dimensões e componentes

\begin{tabular}{|c|c|c|}
\hline \multirow[b]{2}{*}{ Tópicos } & $\begin{array}{l}\text { Epistêmica } \\
\text { (FAE) }\end{array}$ & $\begin{array}{l}\text { - Material de estudo } \\
\text { - Componentes: Situações-problema, Linguagem, Regras } \\
\text { (definiçōes, proposiçōes, procedimentos), Argumentos e } \\
\text { Relaçốes. }\end{array}$ \\
\hline & $\begin{array}{l}\text { Cognitiva } \\
\text { (FAC) }\end{array}$ & $\begin{array}{l}\text { - Estudantes: Significados pretendidos x Significados } \\
\text { declarados } \\
\text {-Componentes: Epistêmicos + Raciocínio Lógico, Leitura e } \\
\text { Interpretaçāo, Análise e Síntese. }\end{array}$ \\
\hline \multirow{4}{*}{ Geral } & $\begin{array}{l}\text { Mediacional } \\
\text { (FAM) }\end{array}$ & $\begin{array}{l}\text { - Material de Estudo } \\
\text { - Componentes: Recursos Didáticos e Tempo Didático. }\end{array}$ \\
\hline & $\begin{array}{l}\text { Interacional } \\
\text { (FAI) }\end{array}$ & $\begin{array}{l}\text { - Material de Estudo, estudantes e pesquisadora } \\
\text { - Componentes: Diálogo e Comunicação, Interação e Autonomia. }\end{array}$ \\
\hline & $\begin{array}{l}\text { Emocional } \\
\text { (FAEMO) }\end{array}$ & $\begin{array}{l}\text { - Estudantes } \\
\text { Componentes: Motivação e Interesse, Envolvimento, Crenças e } \\
\text { Atitudes. }\end{array}$ \\
\hline & $\begin{array}{l}\text { Ecológica } \\
\text { (FAECO) }\end{array}$ & $\begin{array}{l}\text { - Material de Estudo } \\
\text {-Componentes: Escola e Currículo. }\end{array}$ \\
\hline
\end{tabular}

Fonte: elaboração própria

Visando apresentar e refletir sobre como as Ferramentas de Análise foram utilizadas na investigação será apresentado, no segue, uma discussão sobre um dos materiais de estudos, o primeiro deles, que se refere a Figuras Geométricas, considerando a aplicação da proposta de estudos junto a um grupo de 15 estudantes do $9^{\circ}$ ano do Ensino Fundamental de uma Escola Municipal do Município de São Leopoldo/RS. Inicialmente serão apresentadas análises referentes às ferramentas FAE, FAC e FAM, as quais se referem a análise individual do material e, em seguida, a análise geral da proposta por meio das ferramentas FAI, FAEMO e FAECO.

Como já destacado, o primeiro material que compõe a proposta de estudos, se refere ao tópico sobre Figuras Geométricas. Foram retomadas as figuras planas e espaciais, evidenciando seus elementos, características, propriedades, conceitos e possíveis relações. 0 estudo se inicia pela apresentação de imagens (prédios, monumentos, ...) as quais guardam relação ou remetem a representações planas e espaciais e, em seguida, diferenciam-se as formas geométricas por meio de uma animação e atividades online. Em seguida, o estudo é direcionado para os sólidos geométricos, suas planificações e a classificação dos mesmo em poliedros e não poliedros, a partir de um conjunto de atividades online e situações problemas. Por fim, é proposto que o estudante realize uma síntese do que foi trabalhado e dos significados atribuídos, conforme já apresentado na Figura 1 deste artigo.

Assim, no que segue, são apresentadas as análises epistêmica, mediacional, cognitiva, interacional, emocional e ecológica referente ao tópico Figuras Geométricas, considerando a aplicação da proposta de estudos junto aos estudantes como já destacado. 


\subsection{Figuras Geométricas: uma análise epistêmica}

A análise epistêmica realizada no material Figuras Geométricas, assim como a realizada nos demais materiais, tomou como referência a Ferramenta de Análise Epistêmica - FAE, buscando identificar o grau de idoneidade do material nesta perspectiva. No Quadro 2 apresenta-se a análise produzida.

Quadro 2: Análise epistêmica - Figuras Geométricas

\begin{tabular}{|c|c|c|}
\hline $\begin{array}{l}\text { Componentes/ } \\
\text { Idoneidade }\end{array}$ & Indicadores & Análise \\
\hline $\begin{array}{c}\text { Grau de } \\
\text { Idoneidade: } \\
\text { Média }\end{array}$ & $\begin{array}{l}\text { a) apresenta-se uma mostra } \\
\text { representativa e articulada } \\
\text { de situações de } \\
\text { contextualização, exercícios } \\
\text { e aplicações. } \\
\text { b) propõem-se situações de } \\
\text { generalização de problemas } \\
\text { (problematização). }\end{array}$ & $\begin{array}{l}\text { - As atividades propostas se caracterizaram por situações de } \\
\text { contextualização e exercícios, que buscam relacionar as figuras } \\
\text { planas e especiais com imagens reais e objetos do dia a dia. } \\
\text { - Considera-se como uma situação de generalização a atividade na } \\
\text { qual é solicitado identificar os sólidos que rolam e os que não } \\
\text { rolam, encaminhando para a generalização que os que rolam são } \\
\text { os não poliedros e os que não rolam são os poliedros. Outra } \\
\text { situação de generalização se faz presente na atividade que solicita } \\
\text { o estabelecimento da relação existente entre as arestas, faces e } \\
\text { vértices } \\
\text {-O material não apresenta atividades com características de } \\
\text { aplicação, mas sim atividades de contextualização do objeto em } \\
\text { estudo. }\end{array}$ \\
\hline $\begin{array}{l}\text { Linguagens } \\
\text { Grau de } \\
\text { Idoneidade: } \\
\text { Alta }\end{array}$ & $\begin{array}{l}\text { a) uso de diferentes modos } \\
\text { de expressão matemática } \\
\text { (verbal, gráfica, simbólica), } \\
\text { tradução e conversão entre } \\
\text { as mesmas. } \\
\text { b) nível de linguagem } \\
\text { adequado aos estudantes. } \\
\text { c) propõem situações de } \\
\text { expressão matemática e } \\
\text { interpretação. }\end{array}$ & $\begin{array}{l}\text { - O material apresenta uma linguagem adequada ao nível dos } \\
\text { estudantes. } \\
\text { - São utilizadas diferentes formas de linguagem, tendo o } \\
\text { predomínio da natural e gráfica, por meio das representações das } \\
\text { figuras, das planificações e associações aos objetos. }\end{array}$ \\
\hline $\begin{array}{l}\text { Regras } \\
\text { (definições, } \\
\text { proposições, } \\
\text { procedimentos) } \\
\text { Grau de } \\
\text { Idoneidade: } \\
\text { Alta }\end{array}$ & $\begin{array}{l}\text { a) as definições e } \\
\text { procedimentos são claros e } \\
\text { corretos e estão adaptados } \\
\text { ao nível educativo a que se } \\
\text { dirigem. } \\
\text { b) apresentam-se } \\
\text { enunciados e procedimentos } \\
\text { fundamentais do tema para } \\
\text { o nível educativo dado. } \\
\text { c) propõem-se situações } \\
\text { onde os estudantes tenham } \\
\text { que generalizar ou negociar } \\
\text { definições, proposições ou } \\
\text { procedimentos. }\end{array}$ & $\begin{array}{l}\text { - As definições apresentadas e os procedimentos encaminhados } \\
\text { foram organizados de acordo com o nível educativo dos } \\
\text { estudantes. } \\
\text { - Definições, proposições e procedimentos pertinentes e } \\
\text { necessários para o desenvolvimento do trabalho em torno das } \\
\text { figuras geométricas são apresentadas a partir de situações e } \\
\text { atividades que encaminham para formalizações. } \\
\text { - Atividades nas quais é solicitado que sejam estabelecidas } \\
\text { semelhanças e diferenças entre prismas e pirâmides, assim como } \\
\text { entre figuras planas e espaciais, possibilitam reflexões sobre as } \\
\text { definições quando podem ocorrer negociação de significados. }\end{array}$ \\
\hline $\begin{array}{l}\text { Argumentos } \\
\text { Grau de } \\
\text { Idoneidade: } \\
\text { Alta }\end{array}$ & $\begin{array}{l}\text { a) as explicações, } \\
\text { comprovações e } \\
\text { demonstrações são } \\
\text { adequadas ao nível } \\
\text { educativo a que se dirigem. } \\
\text { b) promovem-se situações } \\
\text { onde os estudantes tenham } \\
\text { que argumentar. }\end{array}$ & $\begin{array}{l}\text { - Explicações e demonstrações apresentadas estão de acordo com } \\
\text { o nível educativo dos estudantes, sendo utilizada linguagens } \\
\text { acessíveis, aliadas a exemplos. } \\
\text { - Foram oportunizadas situações que exigiam a apresentação de } \\
\text { argumentação ao longo de todo o material. Atividades com esta } \\
\text { característica foram focadas, principalmente, em situações em que } \\
\text { era necessário diferenciar objetos geométricos a partir de suas } \\
\text { características e das definições e propriedades estudadas. }\end{array}$ \\
\hline Relações & $\begin{array}{l}\text { a) os objetos matemáticos } \\
\text { (problemas, definições, }\end{array}$ & $\begin{array}{l}\text { - Foi solicitado o estabelecimento de relações entre os objetos } \\
\text { estudados e sua presença em elementos do mundo físico. Porém, }\end{array}$ \\
\hline
\end{tabular}




\begin{tabular}{|c|l|l|}
\hline $\begin{array}{c}\text { Grau de } \\
\text { Idoneidade: } \\
\text { Média }\end{array}$ & $\begin{array}{l}\text { proposições) se relacionam } \\
\text { e se conectam entre si. }\end{array}$ & $\begin{array}{l}\text { não se identificou situações que possibilitassem relações entre } \\
\text { outros objetos matemáticos. }\end{array}$ \\
\hline
\end{tabular}

Fonte: adaptado de Lemos (2017).

A partir dos aspectos destacados no quadro 2, é possível observar que os componentes e indicadores epistêmicos estão presentes no material de estudo, considerando que o mesmo foi planejado partindo dos pressupostos do EOS. No que se refere ao componente situações-problema apresenta-se, no material de estudos, um conjunto de situações-problema de contextualização e exercícios, os quais buscam possibilitar aos estudantes identificar e reconhecer as figuras geométricas a partir de imagens do mundo físico (prédios, monumentos, ...) e em objetos do dia a dia de modo que relacionem o conteúdo trabalhado com ideias e representações já conhecidas.

O componente situações-problema foi considerado com idoneidade média, pois, apesar de no material serem propostas atividades que encaminham para generalizações, as mesmas não se caracterizam, propriamente, por uma problematização. As atividades envolvem situações nas quais os estudantes devem identificar características e, a partir delas, consigam distinguir, por exemplo, poliedros e não poliedros (no caso da atividade generalizando que todos os sólidos que rolam (corpos redondos) são não poliedros e os que não rolam são poliedros), como também, que prismas tem duas bases enquanto as pirâmides somente uma.

No que se refere à linguagem, entende-se que foi alcançada uma alta idoneidade, pois foram exploradas as diversas representações dos objetos em estudo, fortemente a presença gráfica, por meio das ilustrações e animações das figuras e suas planificações. Foram explorados aspectos referentes a visualização e percepção dos estudantes, sendo que as atividades online permitiam a manipulação e construção de figuras,

O componente regras também se considerou com uma alta idoneidade, uma vez que todas as definições, conceitos e proposições foram trabalhadas de acordo com o nível educativo dos estudantes. Buscou-se, sempre que possível, apresentar situações ou atividades que introduzissem o estudante na temática, como também, que refletissem sobre elas, sendo que definições e formalizações eram propostas a medida que aspectos visuais, intuitivos e de apropriação informal avançavam.

Entende-se que o componente argumentos teve uma representatividade alta neste material, pois foi proposto um conjunto de situações e atividades as quais possibilitavam aos estudantes identificar e argumentar sobre as semelhanças, diferenças e características dos objetos em estudo, objetivando que os mesmos se apropriassem destas resolvendo situações postas ao longo do estudo.

Já no que se refere ao componente relações, observou-se uma fragilidade no que diz respeito a estabelecer relações com outros objetos matemáticos. No material foi priorizado a identificação dos 
objetos em estudo em possíveis representações no dia a dia, por meio da apresentação de situações, imagens e atividades online, conforme já destacado, o que leva a considerar uma idoneidade média neste componente.

Buscando sintetizar e ilustrar a análise epistêmica produzida, criou-se uma representação pentagonal (Figura 3), inspirada na representação hexagonal apresentada em Godino (2011), onde os vértices são os componentes e apontam um grau de idoneidade máximo, sendo que o polígono inscrito se refere ao grau de idoneidade alcançado no material de estudo.

Figura 3: Representação do grau de Idoneidade Epistêmica alcançado com o material Figuras Geométricas

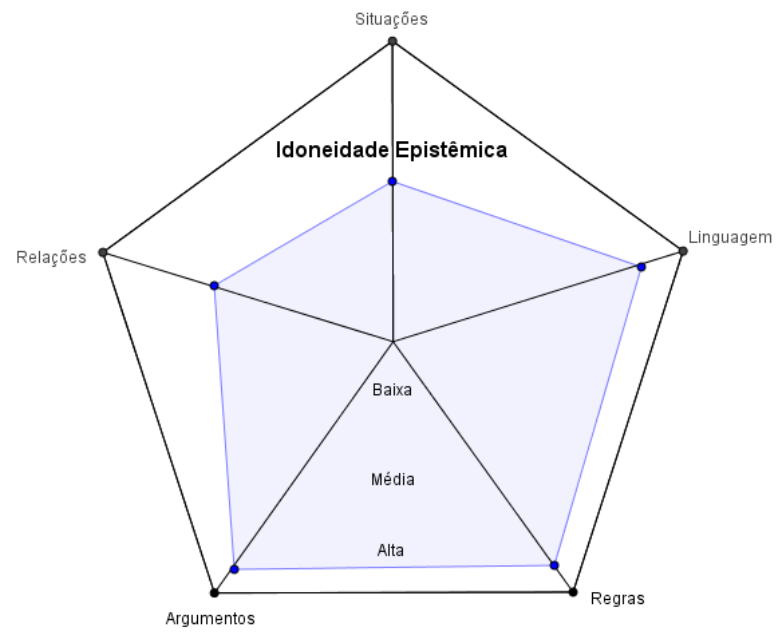

Fonte: Lemos (2017).

A análise epistêmica produzida possibilitou um olhar para como o material de estudo referente a Figuras Geométricas está estruturado, quais aspectos são privilegiados e quais estão fragilizados. Assim, é possível perceber que os componentes estão alinhados ao que é proposto pelo EOS, obtendo uma alta idoneidade em linguagens, regras e argumentos.

Entende-se que o que está sendo apresentado aos estudantes contempla diferentes tipos de representações, sendo que definições, conceitos e proposições são trabalhados a partir de uma linguagem acessível aos estudantes sem perder o rigor matemático necessários. A produção de argumentos é estimulada por meio das atividades, a fim de que os estudantes apresentem e articulem uma argumentação coerente em torno das questões postas.

Já no que se refere aos componentes situações-problemas e relações considerou-se os mesmos com uma idoneidade média, tendo em vista que, apesar de serem contemplados satisfatoriamente no material, não o são plenamente. Nas situações-problema, por exemplo, não são apresentadas situações de aplicação, mas apresentadas diversas situações de contextualização que, entende-se, ser mais pertinente para o estudo em torno das Figuras Geométricas. Quanto às relações buscou-se relacionar 
os objetos em estudo com imagens e até mesmo as relações e diferenças existentes nas próprias figuras estudadas, mas não se apresentou nenhuma relação com outros conteúdos da Matemática.

\subsection{Figuras Geométricas: uma análise mediacional}

Visando refletir sobre os recursos utilizados no material de estudos para o desenvolvimento do trabalho com Figuras Geométricas, realizou-se uma análise a partir dos componentes da Ferramenta de Análise de Mediacional - FAM, recursos e tempo didático, e seus respectivos indicadores. No Quadro 4 apresenta-se uma síntese da análise produzida.

Quadro 4:1 Análise mediacional - Figuras Geométricas

\begin{tabular}{|c|c|c|}
\hline Componentes & Indicadores & Análise \\
\hline $\begin{array}{c}\text { Grau de } \\
\text { Idoneidade: Alta }\end{array}$ & $\begin{array}{l}\text { a) evidencia-se a presença } \\
\text { de materiais adequados ao } \\
\text { desenvolvimento do } \\
\text { processo de ensino e } \\
\text { adaptados ao nível educativo } \\
\text { a que se dirigem; } \\
\text { b) há uma diversificação de } \\
\text { recursos para auxiliar no } \\
\text { processo de ensino, tais } \\
\text { como: audiovisuais, material } \\
\text { concreto, livros, entre outros; } \\
\text { c) propõe-se a organização e } \\
\text { experimentação de situações } \\
\text { práticas. }\end{array}$ & $\begin{array}{l}\text { - Considera-se que o material de estudo proposto está } \\
\text { adequado ao nível educativo dos estudantes, pois utiliza } \\
\text { linguagem acessível mantendo, porém, aspectos formais } \\
\text { quando pertinentes. } \\
\text { - No que se refere aos recursos utilizados destaca-se fortemente } \\
\text { a presença das tecnologias digitais, por meio da estrutura do } \\
\text { próprio material, utilização de imagens, vídeos, animações, } \\
\text { atividades online, aplicações no software Geogebra e objetos de } \\
\text { aprendizagem os quais também privilegiam a manipulação dos } \\
\text { objetos de forma interativa. } \\
\text { - No material se destacam as atividades online que privilegiaram } \\
\text { a visualização e manipulação das figuras geométricas e suas } \\
\text { planificações por meio de associações e de construções } \\
\text { - O objeto de aprendizagem sobre Poliedros que foi utilizado } \\
\text { como um "saiba mais" visando retomar e complementar o que já } \\
\text { havia sido discutido no material também merece destaque, } \\
\text { tendo em vista que oportuniza discussões mais teóricas, com } \\
\text { definições e exemplos, como também, atividades }\end{array}$ \\
\hline $\begin{array}{l}\text { Grau de } \\
\text { Idoneidade: Média }\end{array}$ & $\begin{array}{l}\text { a) apresentam-se situações } \\
\text { de ensino que contemplam } \\
\text { diversas modalidades } \\
\text { (estudo pessoal, cooperativo, } \\
\text { tutorial, presencial); } \\
\text { b) evidencia-se organização } \\
\text { do tempo para intervenção } \\
\text { docente, trabalho autônomo } \\
\text { dos estudantes e momentos } \\
\text { de discussão; } \\
\text { c) dedica-se um tempo maior } \\
\text { para o desenvolvimento dos } \\
\text { conhecimentos, caso os } \\
\text { estudantes apresentem } \\
\text { dificuldade de compreensão. }\end{array}$ & $\begin{array}{l}\text { - A proposta de estudo se caracteriza por um estudo presencial, } \\
\text { que privilegia o trabalho individual, porém conforme já } \\
\text { destacado, a interação entre os estudantes, assim como, com a } \\
\text { pesquisadora se faz presente no processo de estudo. } \\
\text { - Considera-se que o material possibilita desenvolver a } \\
\text { autonomia nos estudantes, uma vez que os mesmos se tornam } \\
\text { responsável pelo seu estudo, estabelecendo seu ritmo de } \\
\text { estudo e aprendizagem. } \\
\text { - Conforme já destacado na análise anterior não há, no material, } \\
\text { atividade especifica que incentive a discussão entre os } \\
\text { estudantes, porém estas foram surgindo no desenvolvimento } \\
\text { dos estudos, tanto entre os estudantes como com a } \\
\text { pesquisadora, sendo também, nestes momentos, trabalhados as } \\
\text { dificuldades, dúvidas e conflitos semióticos apresentados pelos } \\
\text { estudantes. }\end{array}$ \\
\hline
\end{tabular}

Fonte: adaptado de Lemos (2017).

A análise produzida permitiu refletir sobre os recursos utilizados no material de estudos Figuras Geométricas e o tempo didático quando da sua utilização, considerando-se que seus indicadores estão presentes e representados de maneira satisfatória no material. Entende-se que o proposto está de acordo com o nível dos estudantes, assim como, são pertinentes para desenvolver os conceitos, definições, propriedades, estabelecer as relações e procedimentos no estudo das Figuras Geométricas. Ressalta- 
se como positivo a diversidade de recursos utilizados, como atividades online, objetos de aprendizagem, animações, aplicações, links de explicações externos ou situações problemas apresentadas no próprio material. Considera-se que os recursos selecionados e articulados no material oportunizaram aos estudantes um estudo diferenciado potencializando, principalmente, as habilidades de visualização, observação, identificação de características e estabelecimento de relações sendo estas, importantes de serem desenvolvidas ao longo do estudo de Geometria.

\subsection{Figuras Geométricas: uma análise cognitiva}

Visando lançar um olhar para a aprendizagem dos estudantes, os significados produzidos frente aos significados pretendidos e as dificuldades e conflitos apresentados ao longo do estudo sobre Figuras Geométricas, foi proposta uma análise cognitiva, na qual foram considerados tanto os componentes da Ferramenta de Análise Cognitiva - FAC (raciocínio lógico, leitura/interpretação e análise/síntese), como também, os componentes epistêmicos, já discutidos na análise apresentada anteriormente, porém agora com o foco na produção de significado por parte do estudante e não no material proposto.

Para evidenciar a presença destes componentes e indicadores foram apontados os significados pretendidos com o material de estudo, ou seja, o que se espera que os estudantes sejam capazes de fazer/compreender/significar, a partir do conjunto de atividades e situações propostas. Tomando estes significados estabelecidos como referência, buscou-se evidências nos significados declarados pelos estudantes, considerando aqui toda e qualquer manifestação, seja escrita ou falada, correta ou não, na busca por estabelecer o grau de idoneidade nesta dimensão. No Quadro 5 apresenta-se a análise produzida.

Quadro 5: Análise cognitiva: significados pretendidos x declarados para Figuras Geométricas

\begin{tabular}{|c|c|c|}
\hline $\begin{array}{l}\text { Componentes } \\
\text { Epistêmicos- } \\
\text { cognitivos }\end{array}$ & Significados Pretendidos & Significados Declarados \\
\hline $\begin{array}{l}\text { Situações- problemas } \\
\text { Grau de Idoneidade: } \\
\text { Alta }\end{array}$ & $\begin{array}{l}\text {-Identificar figuras geométricas } \\
\text { em situações do cotidiano. } \\
\text {-Associar sólidos geométricos a } \\
\text { objetos. } \\
\text {-Resolver as situações propostas, } \\
\text { utilizando os conceitos, } \\
\text { procedimentos e argumentos } \\
\text { necessários. }\end{array}$ & $\begin{array}{l}\text { - Os estudantes identificaram as figuras geométricas, } \\
\text { indicando como exemplos caixas de papelão, } \\
\text { casquinha de sorvete, bola, cubo mágico, dado, entre } \\
\text { outros. } \\
\text {-A maioria dos estudantes conseguiu resolver } \\
\text { corretamente as situações propostas, apresentando } \\
\text { maiores dificuldades onde era necessário apresentar } \\
\text { justificativas com base em argumentação. }\end{array}$ \\
\hline $\begin{array}{l}\text { Grau de Idoneidade: } \\
\text { Alta }\end{array}$ & $\begin{array}{l}\text { - Identificar os sólidos com suas } \\
\text { planificações. } \\
\text { - Associar uma imagem a sua } \\
\text { representação (esboços, vistas } \\
\text { laterais, superiores...). } \\
\text { - Utilizar linguagem matemática } \\
\text { adequada na solução das } \\
\text { situações. }\end{array}$ & $\begin{array}{l}\text { - No que se refere a planificações (representação } \\
\text { figural), os estudantes apresentaram facilidades em } \\
\text { identificá-las, relacionando figuras especiais a sua } \\
\text { planificação. } \\
\text { - Nas atividades de associação de imagem a } \\
\text { representações como esboços e vistas, apresentaram } \\
\text { dificuldades com as vistas laterais e superiores. } \\
\text { - Foi possível perceber que prevaleceu a linguagem } \\
\text { natural, sendo utilizadas, também, representações } \\
\text { figurais, por meio de esboços das figuras geométricas. }\end{array}$ \\
\hline
\end{tabular}




\begin{tabular}{|c|c|c|}
\hline & & $\begin{array}{l}\text { - Quanto a utilizar a linguagem matemática } \\
\text { adequadamente, nem sempre os estudantes utilizaram } \\
\text { as denominações adequadas (por exemplo, "ponta" } \\
\text { designando vértice). }\end{array}$ \\
\hline $\begin{array}{l}\text { Regras (definições, } \\
\text { proposições, } \\
\text { procedimentos) }\end{array}$ & $\begin{array}{l}\text {-Identificar objetos que rolam e } \\
\text { não rolam. } \\
\text {-Identificar figuras planas e não } \\
\text { planas. } \\
\text {-Identificar poliedros e não } \\
\text { poliedros. } \\
\text {-Identificar as faces, arestas e } \\
\text { vértices. } \\
\text { - Identificar objetos a partir de } \\
\text { seus elementos, definição ou } \\
\text { características. }\end{array}$ & $\begin{array}{l}\text { - Todos os estudantes conseguiram identificar os } \\
\text { objetos que rolam e não rolam na atividade proposta, } \\
\text { como também identificar as figuras planas e não } \\
\text { planas. } \\
\text { - Nas atividades de identificar os poliedros, apenas } \\
\text { dois estudantes apresentaram dificuldades, sendo que } \\
\text { indicaram como não poliedro, os prismas que tinham } \\
\text { como base um octógono e eneágono, que na } \\
\text { representação poderiam parecer "arredondado" } \\
\text { desconsiderando as faces na identificação. O outro } \\
\text { estudante indicou como não poliedro as pirâmides. } \\
\text { - Quanto às faces, arestas e vértices, os estudantes, } \\
\text { incialmente, apresentaram dificuldades. A partir da } \\
\text { atividade que possibilitava movimentar e destacava as } \\
\text { partes a partir do selecionado, os alunos não } \\
\text { apresentaram maiores dificuldades. }\end{array}$ \\
\hline $\begin{array}{c}\text { Grau de Idoneidade: } \\
\text { Média }\end{array}$ & $\begin{array}{l}\text {-Diferenciar figuras planas e } \\
\text { espaciais. } \\
\text {-Diferenciar poliedros e não } \\
\text { poliedros. } \\
\text { - Diferenciar esfera e cubo; } \\
\text {-Diferenciar cone e cilindro. } \\
\text {-Apresentar as semelhanças e } \\
\text { diferenças de prismas e } \\
\text { pirâmides. }\end{array}$ & $\begin{array}{l}\text {-Os estudantes diferenciaram as figuras planas das } \\
\text { espaciais utilizando principalmente os argumentos de } \\
\text { que as planas têm duas dimensões (bidimensionais) e } \\
\text { as espaciais três dimensões (tridimensionais). } \\
\text {-Também argumentaram dizendo que as planas têm } \\
\text { somente largura e altura e as espaciais profundidade, } \\
\text { largura e altura. } \\
\text {-Os argumentos em torno das diferenças dos poliedros } \\
\text { e não poliedros foram relativos a poliedros terem face, } \\
\text { vértices e arestas e os não poliedros terem superfícies } \\
\text { curvas, como também que os não poliedros são corpos } \\
\text { redondos. } \\
\text {-As principais diferenças apontadas para a esfera e o } \\
\text { cubo foram que a esfera rola, e o cubo não, e que a } \\
\text { esfera é um corpo redondo e o cubo um poliedro. Já } \\
\text { como semelhança destacaram os dois como sólidos } \\
\text { geométricos e figuras espaciais. } \\
\text {-A principal diferença apontada pelos alunos para o } \\
\text { cone e o cilindro é que o cone tem "ponta" ou "bico", } \\
\text { também foi indicado que o cilindro "tem duas bases" e } \\
\text { o cone uma. } \\
\text {-No que se refere as pirâmides e prismas, os alunos } \\
\text { apresentaram dificuldades iniciais. A pesquisadora } \\
\text { retomou a imagem apresentada e os mesmos } \\
\text { observaram que os prismas "têm duas bases" } \\
\text { enquanto as pirâmides têm uma só e tem "bico" ou } \\
\text { "ponta". Como semelhanças destacaram que ambas } \\
\text { são poliedros e figuras espaciais. }\end{array}$ \\
\hline $\begin{array}{l}\text { Relações } \\
\text { Grau de Idoneidade: } \\
\text { Média }\end{array}$ & $\begin{array}{l}\text {-Compreender a relação entre } \\
\text { prismas e pirâmides. } \\
\text {-Estabelecer relações entre as } \\
\text { figuras geométricas estudadas. }\end{array}$ & $\begin{array}{l}\text {-Os estudantes relacionaram os prismas e pirâmides } \\
\text { como sendo poliedros, mas formados por elementos } \\
\text { diferentes, assim como estabeleceram relações entre } \\
\text { algumas figuras geométricas, como os corpos } \\
\text { redondos, os poliedros, figuras planas e espaciais. }\end{array}$ \\
\hline $\begin{array}{l}\text { Raciocínio Lógico } \\
\text { Grau de Idoneidade: } \\
\text { Média }\end{array}$ & $\begin{array}{l}\text { - Observar e apresentar uma } \\
\text { semelhança entre esfera e cubo. } \\
\text { - Observar e apresentar uma } \\
\text { diferença entre esfera e cubo. } \\
\text { - Observar e diferenciar cone e } \\
\text { cilindro. }\end{array}$ & $\begin{array}{l}\text { - No que se refere a observar as características e } \\
\text { elementos das figuras trabalhadas para posteriormente } \\
\text { apresentar uma argumentação em torno da mesma, os } \\
\text { estudantes não apresentaram dificuldades em } \\
\text { identificá-las, porém tinham dificuldades de expressar } \\
\text { o que tinham observado. }\end{array}$ \\
\hline
\end{tabular}




\begin{tabular}{|c|c|c|}
\hline $\begin{array}{l}\text { Grau de Idoneidade: } \\
\text { Média }\end{array}$ & $\begin{array}{l}\text { - Conseguir ler e interpretar } \\
\text { adequadamente as informações } \\
\text { e situações propostas no } \\
\text { material. } \\
\text { - Associar um objeto a suas } \\
\text { representações, sendo } \\
\text { apresentadas em diferentes } \\
\text { formas. } \\
\text { - Identificar, analisar e refletir } \\
\text { sobre as informações da tabela } \\
\text { apresentada para estabelecer as } \\
\text { semelhanças e diferenças entre } \\
\text { pirâmides e prismas. }\end{array}$ & $\begin{array}{l}\text { - Entende-se que os estudantes apresentaram um bom } \\
\text { desempenho no que se refere a leitura do material, } \\
\text { sempre realizada com atenção e registrando o que } \\
\text { consideravam mais importante. Porém em algumas } \\
\text { situações apresentavam dificuldades de interpretação } \\
\text { do que era para ser feito, principalmente quando o } \\
\text { questionamento ou atividade não estava em forma de } \\
\text { "questão" e sim apresentada no contexto de estudo. } \\
\text { - Considera-se que os estudantes transitaram com } \\
\text { facilidade entre as diferentes representações das } \\
\text { figuras trabalhadas, tendo um predomínio da gráfica, } \\
\text { por meio de imagens e da língua natural, pela } \\
\text { característica do estudo. }\end{array}$ \\
\hline $\begin{array}{l}\text { Análise/Síntese } \\
\text { Grau de Idoneidade: } \\
\text { Baixa }\end{array}$ & $\begin{array}{l}\text { - Realizar síntese durante e ao } \\
\text { final do estudo, conseguindo } \\
\text { identificar e expressar o que foi } \\
\text { aprendido. }\end{array}$ & $\begin{array}{l}\text { - Este componente se apresentou como um dos mais } \\
\text { dificeis para os estudantes, pois não estão habituados } \\
\text { a ter que produzir uma análise do estudo realizado ou } \\
\text { produzir uma síntese. Seus melhores desempenhos se } \\
\text { referem a questões onde tenham que responder "algo" } \\
\text { e não buscar refletir e, a partir do estudo, se expressar } \\
\text { sobre algo. Ressalta-se que estes aspectos foram } \\
\text { sendo trabalhados ao longo do estudo, porém como } \\
\text { este é o primeiro material ficou bem evidenciada a } \\
\text { dificuldade. }\end{array}$ \\
\hline
\end{tabular}

Fonte: adaptado de Lemos (2017).

Com base no que foi apresentado no quadro de análise (Quadro 5) é possível perceber que os significados declarados pelos estudantes se aproximaram significativamente dos pretendidos.

Considera-se que o componente situações-problemas obteve uma alta idoneidade, pois os estudantes conseguiram resolver corretamente as situações propostas, principalmente no que se refere ao identificar figuras e sólidos geométricos em situações cotidianas e estabelecer diferenças e semelhanças entre elas.

O componente linguagens foi considerado com um grau de idoneidade alto, pois entende-se que os estudantes conseguiram trabalhar com diferentes representações de um mesmo objeto, contemplando tanto linguagem natural, gráfica e por representações figurais de esboços produzidos por eles.

O componente regras também foi considerado com uma idoneidade alta, pois entendeu-se que os estudantes conseguiram compreender e mobilizar as definições, proposições e procedimentos a fim de resolver as situações propostas ao longo do estudo sobre Figuras Geométricas.

No que se refere aos componentes argumentos, relações, raciocínio lógico, leitura e interpretação considerou-se a idoneidade média, pois entende-se que, apesar dos mesmos terem sidos contemplados, poderiam ter sido explorados com mais intensidade no material, com um maior número de atividades que envolvessem justificativas e argumentações. Respostas apresentadas pelos estudantes envolvendo os componentes apontados e que, em algumas situações, foram incompletas ou 


\section{revemop}

parcialmente corretas, ou ainda apresentaram conflitos semióticos. Segundo Godino (2013) este tipo de conflito se refere a disparidade entre o significado atribuído pelo estudante (pessoal/declarado) frente ao significado de referência (institucional/pretendido).

Considerou-se o componente análise/síntese com uma idoneidade baixa, já que os estudantes não conseguiram realizar com facilidade, neste primeiro material, a produção de análises e sínteses a fim de compreender, expressar e comunicar o que estava sendo estudado. Uma atividade que pode ilustrar esta dificuldade se refere ao final do estudo, quando foi solicitado que descrevessem o que conseguiram aprender com o material. As respostas, em geral, foram bem sucintas e ficaram em torno da indicação da denominação do que tinha sido tratado no material.

A partir do que foi apresentado e discutido, considera-se que a análise produzida permitiu um olhar para o que se pretendia e o que foi efetivamente alcançado pelos estudantes, possibilitando observar, analisar e refletir sobre as potencialidades e fragilidades do material, referente aos significados pretendidos, dos significados manifestados pelos estudantes, bem como identificar as possíveis tensões/relações e conflitos semióticos nos significados atribuídos pelos estudantes. Assim, entende-se que os significados pretendidos foram em parte alcançados, mas não o suficiente para se considerar uma idoneidade alta, mas se fazendo presente de maneira satisfatória nos componentes epistêmicos e cognitivos, exceto na Análise/Síntese, conforme já destacado.

Assim, buscando sintetizar e ilustrar a análise produzida, criou-se uma representação octogonal (Figura 4), onde os vértices são os componentes e o polígono inscrito refere-se ao grau de idoneidade alcançado frente aos significados pretendidos e declarados.

Figura 4:2 Representação do grau de Idoneidade Cognitiva alcançado com o material Figuras Geométricas

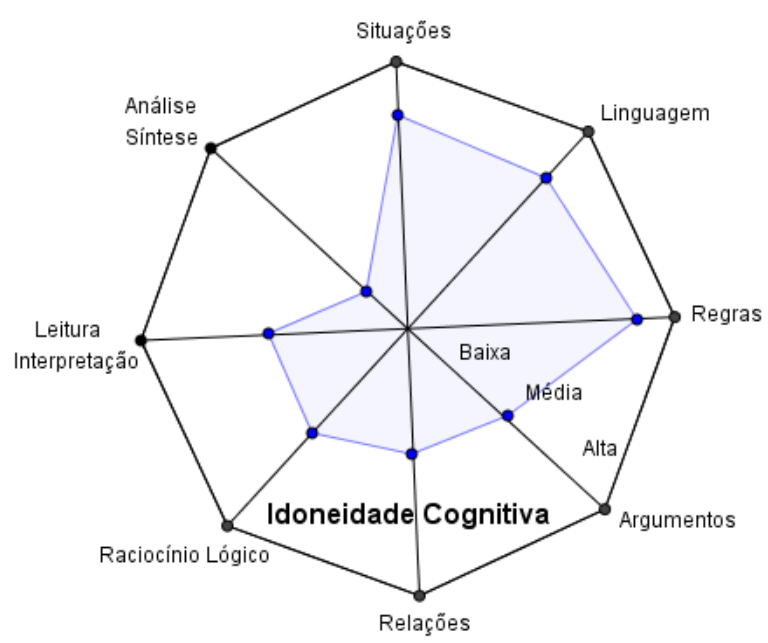

Fonte: Lemos (2017). 
As análises produzidas sobre o material de estudos Figuras Geométricas permitiram refletir sobre a forma de condução do estudo, os recursos utilizados, os significados pretendidos com o conteúdo do material e os declarados pelos estudantes.

Considera-se que os componentes propostos pelas ferramentas de análise epistêmica, mediacional e cognitiva, se fizeram presente no material de maneira satisfatória. No que se refere a dimensão epistêmica, destaca-se os componentes linguagens, regras e argumentos com uma alta idoneidade, sendo que os dois primeiros também alcançaram uma alta idoneidade na dimensão cognitiva, o que indica uma produção, pelos estudantes, de significados fortemente relacionado com os significados pretendidos.

O único componente que apresentou uma baixa idoneidade foi análise e síntese, sendo que os demais componentes foram considerados com uma média idoneidade (situações-problema, relações, raciocínio lógico, leitura e interpretação).

Neste contexto, entende-se que os resultados alcançados com o material de estudos sobre Figuras Geométricas foram positivos, pois os estudantes conseguiram atingir grande parte dos significados pretendidos, destacando seus desempenhos na mobilização e articulação das definições e propriedades para resolver as situações-problema envolvidos no estudo, como também, na diferenciação e no estabelecimento de relações entre figuras planas e espaciais. Porém, mais uma vez se destacam as dificuldades apresentadas nas atividades que envolviam argumentação e justificativas.

No que que segue apresenta-se as análises referente as dimensões interacional, emocional e ecológica, por meio das ferramentas FAI, FAEMO e FAECO. Ressalta-se que nestas análises laçou-se um olhar para a proposta como um todo, tendo em vista, que os resultados evidenciados nestas dimensões, tem características similares em todos os materiais.

\subsection{Proposta de Estudos de Recuperação de Geometria: uma análise interacional}

Buscando identificar e analisar as interações ocorridas entre os estudantes, a pesquisadora e 0 material, a partir dos registros capturados em áudio e vídeo, das observações da pesquisadora e registrados em diário, utilizam-se, aqui, os componentes e indicadores da Ferramenta de Análise Interacional - FAl: diálogo/comunicação, interação e autonomia, objetivando refletir sobre o grau de idoneidade das interações produzidas ao longo dos estudos. No Quadro 6 apresenta-se a análise produzida. 
Quadro 6: Análise Interacional da Proposta de Estudos de Recuperação

\begin{tabular}{|c|c|c|}
\hline Componentes & Indicadores & Análise \\
\hline $\begin{array}{l}\text { Diálogo } \\
\text { Comunicação } \\
\text { Grau de } \\
\text { Idoneidade: } \\
\text { Média }\end{array}$ & $\begin{array}{l}\text { a) propõem-se momentos de } \\
\text { discussão coletiva. } \\
\text { b) há espaço para } \\
\text { intervenção docente e } \\
\text { discente. } \\
\text { c) promove-se oportunidades } \\
\text { de discussão/superação dos } \\
\text { conflitos semióticos através } \\
\text { da argumentação. }\end{array}$ & $\begin{array}{l}\text { - Em grande parte dos materiais de estudos, são propostas } \\
\text { situações as quais os estudantes tenham que discutir em grupo. } \\
\text { Além destes momentos previstos, pode-se observar que a } \\
\text { comunicação e o diálogo entre os estudantes se fizeram } \\
\text { presente, assim como com a pesquisadora, quando se } \\
\text { deparavam com alguma situação que apresentassem dúvidas. }\end{array}$ \\
\hline $\begin{array}{c}\text { Grau de } \\
\text { Idoneidade: Alta }\end{array}$ & $\begin{array}{l}\text { a) propõem-se situações que } \\
\text { ampliam as relações de } \\
\text { comunicação com outros } \\
\text { alunos, com o professor, com } \\
\text { o material de ensino. } \\
\text { b) organizam-se situações } \\
\text { para identificação e resolução } \\
\text { de conflitos semióticos } \\
\text { mediante interpretação de } \\
\text { significados. }\end{array}$ & $\begin{array}{l}\text { - A interação entre os sujeitos se fez presente durante todo o } \\
\text { estudo. Os estudantes interagiram com a pesquisadora, não só } \\
\text { quando apresentavam dificuldades em relação ao objeto de } \\
\text { estudo, mas também, para orientações de como deveriam } \\
\text { proceder com as atividades. } \\
\text { - Quanto à interação com o material, os estudantes se } \\
\text { adaptaram bem à proposta de trabalho. Realizavam a leitura do } \\
\text { material, registrando anotações que consideravam importantes } \\
\text { e resolviam as atividades. } \\
\text { - No que se refere aos conflitos semióticos, estes foram sendo } \\
\text { identificados pela pesquisadora por meio da observação } \\
\text { durante o estudo ou quando expressado pelos próprios } \\
\text { estudantes. }\end{array}$ \\
\hline $\begin{array}{l}\text { Autonomia } \\
\text { Grau de } \\
\text { Idoneidade: Alta }\end{array}$ & $\begin{array}{l}\text { a) propõem-se momentos em } \\
\text { que os discentes assumam a } \\
\text { responsabilidade do estudo; } \\
\text { b) apresentam-se situações } \\
\text { que possibilitem o estudante } \\
\text { raciocinar, fazer conexões, } \\
\text { resolver problemas e } \\
\text { comunicá-los. }\end{array}$ & $\begin{array}{l}\text { - Entende-se que este componente se faz fortemente presente } \\
\text { na estrutura da proposta de estudo, uma vez que a mesma } \\
\text { proporciona aos estudantes espaços para o desenvolvimento } \\
\text { da autonomia para o estudo, já que os materiais são individuais, } \\
\text { o que permite que sigam o seu ritmo de aprendizagem. }\end{array}$ \\
\hline
\end{tabular}

Fonte: adaptado de Lemos (2017).

Considera-se que os componentes e indicadores propostos pela FAl estão contemplados na implementação da proposta de estudos, tendo maior destaque para Interação e Autonomia, entendidas como idoneidades altas.

Ressalta-se o componente Autonomia como um ponto forte, pois como pode ser observado no registro apresentado na Figura 5, os estudantes estão no mesmo material de estudo, porém em atividades distintas, ou seja, cada um está realizando as atividades de acordo com o seu ritmo de aprendizagem.

Figura 5: Registro dos estudantes em seus estudos
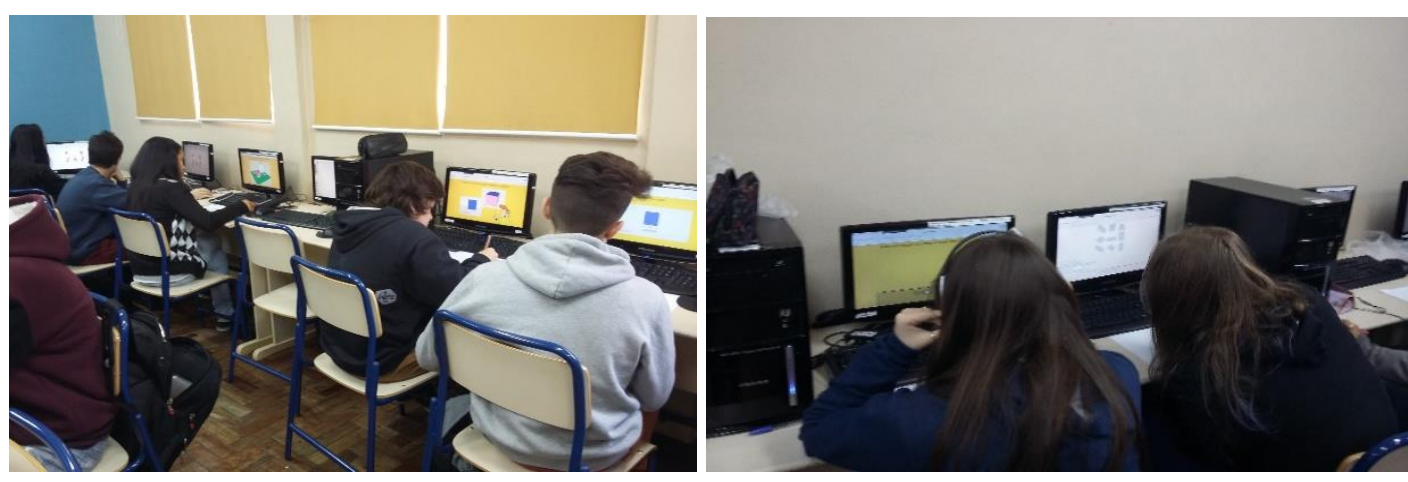

Fonte: Lemos (2017, p. 316). 
No que se refere ao componente diálogo e comunicação considerou-se a idoneidade média, pois não são todos os materiais de estudos que preveem atividade que estimule uma discussão entre os estudantes, o que se identificou como uma fragilidade da proposta, com indicativo de futuras intervenções no sentido de aprimorá-la. Buscando sintetizar e ilustrar a análise interacional produzida, criou-se uma representação triangular (Figura 6), onde os vértices são os componentes e o polígono inscrito refere-se ao grau de idoneidade alcançado no material de estudo.

Figura 6: Representação do grau de Idoneidade Interacional alcançado

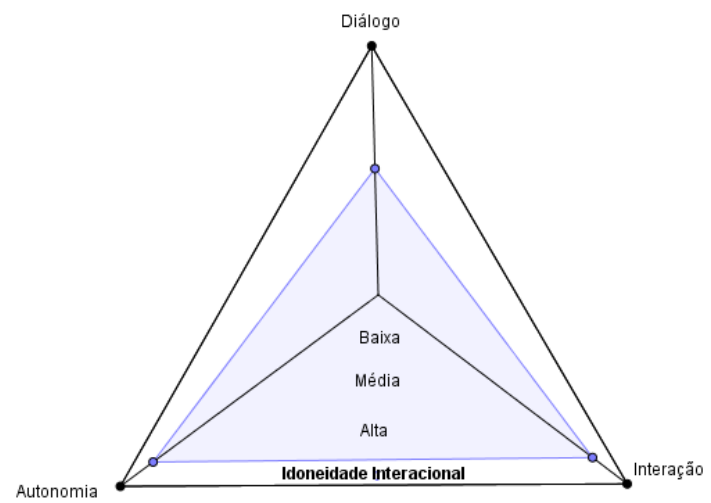

Fonte: Lemos (2017).

\subsection{Proposta de estudos de recuperação de geometria: uma análise emocional}

No que se refere as questões atitudinais dos estudantes frente ao trabalho desenvolvido, lançase um olhar para a dimensão emocional e se propõem uma análise destes aspectos tomando como referência os componentes e indicadores da Ferramenta de Análise Emocional - FAEMO: motivação/interesse, envolvimento e crenças/atitudes. As evidências para esta análise foram buscadas nos registros em áudio e vídeo realizados, mas, principalmente, nas observações da pesquisadora durante os encontros. Apresenta-se, no Quadro 7, a análise produzida.

Quadro 7: Análise Emocional da Proposta de Estudos de Recuperação

\begin{tabular}{|c|l|l|}
\hline Componentes & \multicolumn{1}{|c|}{ Indicadores } & \multicolumn{1}{c|}{ Análise } \\
\hline \multirow{4}{*}{ Motivação/Interesse } & $\begin{array}{l}\text { a) incentiva-se o trabalho } \\
\text { cooperativo. } \\
\text { b) propõem-se situações } \\
\text { adaptadas ao nível educativo } \\
\text { dos alunos, levando em } \\
\text { consideração seus interesses. } \\
\text { c) as situações apresentadas } \\
\text { estimularam o interesse dos } \\
\text { estudantes. }\end{array}$ & $\begin{array}{l}\text { - O trabalho cooperativo não está explicitado em } \\
\text { todos os materiais, mas como já destacado as } \\
\text { interações ocorreram ao longo do estudo. } \\
\text {-Considera-se que as atividades propostas } \\
\text { despertaram o interesse dos estudantes, } \\
\text { principalmente, as animações, atividades online e } \\
\text { objetos de aprendizagem. }\end{array}$ \\
& $\begin{array}{l}\text { a) apresentam-se configurações } \\
\text { didáticas que proporcionam o } \\
\text { envolvimento dos estudantes. }\end{array}$ & $\begin{array}{l}\text { - Foi possível perceber o envolvimento dos } \\
\text { estudantes no processo de estudo. Foram se } \\
\text { adaptando rapidamente à proposta de estudo, } \\
\text { lendo com atenção o material e realizando as } \\
\text { E) estimulam-se as relações } \\
\text { Envolvimento }\end{array}$ \\
$\begin{array}{l}\text { Grau de } \\
\text { entre professor-aluno, aluno- } \\
\text { aluno, professor-professor para }\end{array}$ & atividades. \\
\hline
\end{tabular}




\begin{tabular}{|c|c|c|}
\hline & $\begin{array}{l}\text { qualificar o processo de ensino } \\
\text { e aprendizagem. }\end{array}$ & \\
\hline $\begin{array}{c}\text { Crenças/Atitudes } \\
\text { Grau de } \\
\text { Idoneidade: Alta }\end{array}$ & $\begin{array}{l}\text { a) promove-se um trabalho que } \\
\text { supere a visão da Matemática } \\
\text { como algo difícil e acessível a } \\
\text { poucos. }\end{array}$ & $\begin{array}{l}\text { - Nos materiais produzidos buscou-se trabalhar } \\
\text { com os conceitos, propriedades e procedimentos } \\
\text { de forma acessivel aos estudantes e, sempre que } \\
\text { possível, relacionado com situações de } \\
\text { contextualização e problematização do mundo } \\
\text { que os cerca. }\end{array}$ \\
\hline
\end{tabular}

Fonte: adaptado de Lemos (2017).

A partir da análise produzida considera-se que os componentes e indicadores da FAEMO se fizeram presente tendo uma alta idoneidade no que se refere ao envolvimento e crenças/atitudes, evidenciados por meio da efetiva participação dos estudantes nas atividades, as quais realizaram com dedicação e atenção, demonstrando interesse na temática, assim como em solucionar as situações propostas. Cabe ressaltar, também, a facilidade dos estudantes no trabalho com as tecnologias digitais, demonstrando assim um maior envolvimento nas atividades online e objetos de aprendizagem.

No que se refere ao componente motivação/interesse considerou-se como uma média idoneidade, pelo indicador sobre o incentivo do trabalho cooperativo, que não está previsto explicitamente em todos os materiais. Por outro lado, a motivação dos participantes relacionada ao interesse em aprender e se preparar para provas de seleção foi elemento que colaborou fortemente para o desenvolvimento do trabalho. Buscando sintetizar e ilustrar a análise interacional produzida, criou-se uma representação triangular (Figura 7), onde os vértices são os componentes e o polígono inscrito refere-se ao grau de idoneidade alcançado no material de estudo.

Figura 7: Representação do grau de Idoneidade Emocional alcançado

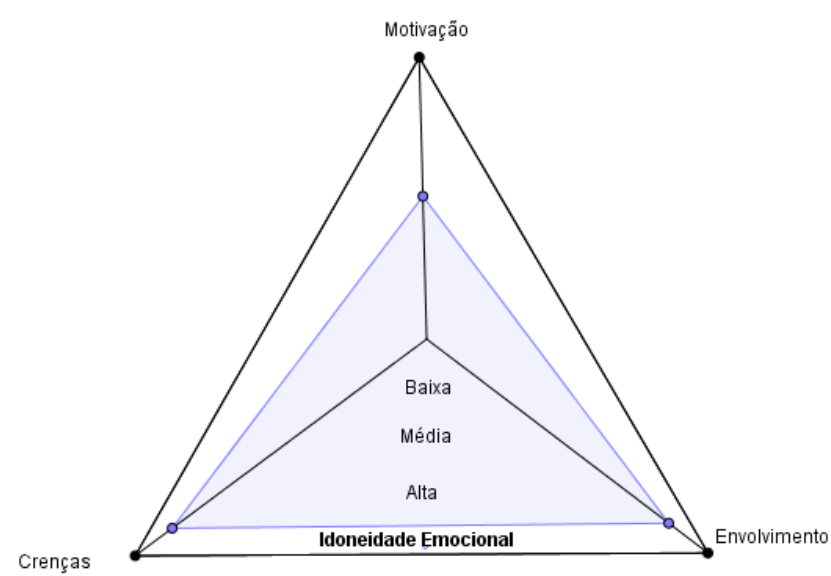

Fonte: Lemos (2017).

Considera-se que as opiniões dos estudantes sobre o trabalho desenvolvido, que foram tomadas ao longo e ao final do trabalho, estão contempladas dentro desta dimensão emocional, pois suas respostas estão baseadas em suas motivações, envolvimento e comprometimento com a proposta de estudos. 


\subsection{Proposta de estudos de recuperação de geometria: uma análise ecológica}

Buscando refletir e analisar sobre o grau de adequação do material de estudos frente aos significados institucionais de referência, ou seja, o que está posto nos documentos oficiais e também 0 que é preconizado na escola, propõem-se esta análise considerando os componentes e indicadores da Ferramenta de Análise Ecológica - FAECO: currículo, escola e sociedade. No que segue, apresenta-se, no Quadro 8 , a análise produzida.

Quadro 8: Análise Ecológica da Proposta de Estudos de Recuperação

\begin{tabular}{|c|c|c|}
\hline Componentes & Indicadores & Análise \\
\hline $\begin{array}{c}\text { Escola } \\
\text { Grau de } \\
\text { Idoneidade: } \\
\text { Média }\end{array}$ & $\begin{array}{l}\text { a) espaço de desenvolvimento e } \\
\text { aprendizagem envolvendo } \\
\text { experiências contempladas nesse } \\
\text { processo (aspectos culturais, } \\
\text { cognitivos, afetivos, sociais e } \\
\text { históricos); } \\
\text { b) constitui-se em espaço que } \\
\text { possibilita o uso de metodologias, } \\
\text { recursos diversificados e tecnologia; } \\
\text { c) ambiente que incentiva a formação } \\
\text { de valores e pensamento crítico. }\end{array}$ & $\begin{array}{l}\text { - Considera-se que a proposta contempla a } \\
\text { utilização de metodologias e recursos diversos, } \\
\text { principalmente no que se refere ao uso das } \\
\text { tecnologias digitais, por meio das animações, } \\
\text { atividades online e objetos de aprendizagem, assim } \\
\text { como aplicações no software Geogebra. } \\
\text { - Quanto à formação de valores e pensamento } \\
\text { crítico, entende-se que as atividades propostas não } \\
\text { tiveram esta característica. }\end{array}$ \\
\hline $\begin{array}{c}\text { Grau de } \\
\text { Idoneidade: } \\
\text { Alta }\end{array}$ & $\begin{array}{l}\text { a) o ensino está adaptado as } \\
\text { orientações da escola, aos } \\
\text { documentos oficiais. } \\
\text { b) apresentam-se situações de } \\
\text { problematização e contextualização, } \\
\text { realizando conexões com outros } \\
\text { conteúdos. } \\
\text { c) valoriza-se a pluralidade cultural } \\
\text { dos alunos. } \\
\text { d) os conteúdos e a avaliação } \\
\text { atendem as diretrizes curriculares. } \\
\text { e) o ensino é coerente ao nível } \\
\text { educativo a que se dirige. }\end{array}$ & $\begin{array}{l}\text { - O material de estudo foi planejado levado em } \\
\text { consideração as indicações dos documentos } \\
\text { oficiais, assim como os objetivos estabelecidos pela } \\
\text { escola para a temática. } \\
\text {-Buscou-se trabalhar no material com situações de } \\
\text { contextualização, buscando estabelecer conexões e } \\
\text { relações dentro do próprio conteúdo. Não se } \\
\text { identificou situações que possibilitassem conexão } \\
\text { com outros conteúdos. } \\
\text { - No que se refere à avaliação, a mesma ocorreu } \\
\text { durante todo o processo de estudo. A aprendizagem } \\
\text { ou os conflitos semióticos foram sendo } \\
\text { evidenciados nas atividades resolvidas pelos } \\
\text { estudantes, conforme já discutido na análise } \\
\text { cognitiva. }\end{array}$ \\
\hline Sociedade & $\begin{array}{l}\text { a) percebe-se a valorização de } \\
\text { aspectos da vida dos estudantes no } \\
\text { ambiente escolar. } \\
\text { b) percebe-se a presença da } \\
\text { comunidade no processo de } \\
\text { escolarização promovida pela escola. }\end{array}$ & Não se aplica. \\
\hline
\end{tabular}

Fonte: adaptado de Lemos (2017).

Conforme já destacado, os materiais de estudos foram planejados considerando os objetivos estabelecidos pelos documentos oficiais, assim o componente currículo se faz fortemente presente e alinhado com o que está estabelecido e o que é proposto no material. Porém, cabe destacar que além destes objetivos já apontados pelos documentos, foram traçados objetivos próprios, apresentados nas análises epistêmicas como os significados institucionais pretendidos, dando mais ênfase a objetivos que encaminhassem para a argumentação e para o estabelecimento de relações, já que os postos nos 


\section{revemop}

documentos se referiam mais a aspectos procedimentais, atendendo fortemente ao componente das regras.

No que se refere ao componente escola considerou-se com uma idoneidade média, pelo fato da proposta de trabalho desenvolvida no material não contemplar aspectos para a formação de valores e pensamento crítico, o que se identificou como uma fragilidade no material que deve ser repensada, visando um aprimoramento.

Entende-se que o componente sociedade não se aplica à proposta aqui discutida, uma vez que se está analisando o material produzido e a implementação deste com estudantes, ou seja, se consiste em uma ação externa que se inseriu na escola.

Assim, considera-se que a dimensão ecológica se fez presente por meio de seus componentes e indicadores de maneira satisfatória, apresentando uma média idoneidade na proposta de estudos tendo em vista que a mesma foi construída levando em consideração o que está estabelecido pelos currículos e nos documentos oficiais, porém não contempla um conjunto de situações que estimulem a formação de valores e pensamento crítico.

Considera-se que as análises produzidas, a partir das seis dimensões da Idoneidade Didática, seus componentes e indicadores, permitiram um olhar tanto para o material produzido, para as situações de aprendizagem, adequadas ou não, que o mesmo possibilitou, como também, às demais relações estabelecidas em um processo de ensino e aprendizagem, aqui representadas pelas dimensões da Idoneidade Didática, no âmbito do Enfoque Ontosemiótico do Conhecimento e da Instrução Matemática. Assim, ressalta-se que estas análises evidenciaram, o potencial dos pressupostos estabelecidos pelo EOS como ferramenta para um olhar ao processo de ensino e aprendizagem como um todo, desde 0 seu planejamento, passando pela implementação junto aos estudantes chegando a sua avaliação.

Assim, apresenta-se na Figura 8, o comportamento das distintas dimensões na representação hexagonal da Idoneidade Didática, buscando, assim, uma síntese da idoneidade alcançada com 0 desenvolvimento e implementação da proposta de estudos de recuperação para a Geometria dos anos finais do Ensino Fundamental. 
Figura 8: Idoneidade Didática alcançada na proposta de estudos de recuperação

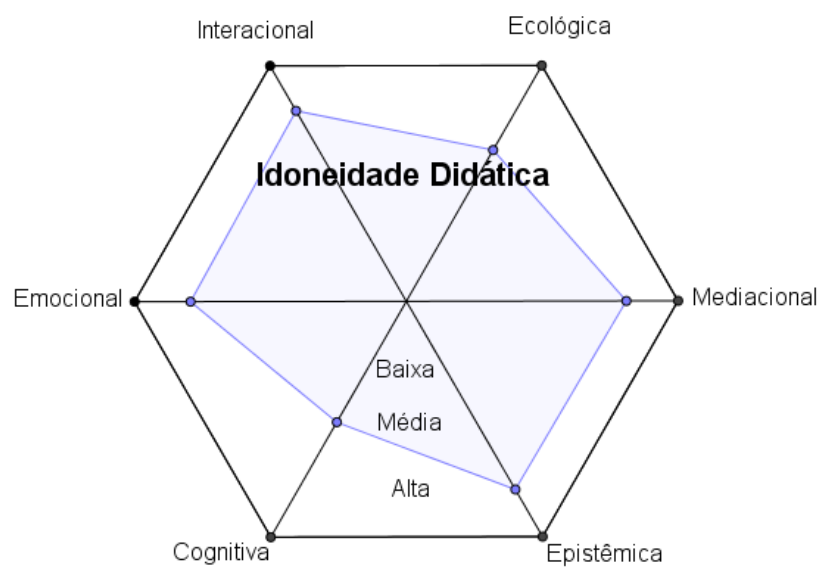

Fonte: Lemos (2017).

\section{Considerações Finais}

O presente artigo teve como objetivo apresentar um recorte dos resultados de uma investigação que tomou como referência as ferramentas do Enfoque Ontosemiótico (EOS) para o desenvolvimento e implementação de uma proposta de estudos de recuperação para a Geometria dos anos finais do Ensino Fundamental.

Ressalta-se que as análises tiveram tanto um olhar específico para o objeto em estudo, como uma visão global do desenvolvimento da proposta de estudo, o que permitiu sínteses importantes e reveladoras sobre o material produzido, o trabalho dos estudantes e mesmo da pesquisadora, o que evidencia a importância da utilização das ferramentas de análises propostas pelo EOS.

Neste sentido, especificamente sobre o material de estudos Figuras Geométricas, as analises permitiram refletir sobre a forma de condução do estudo, os recursos utilizados, os significados pretendidos com o conteúdo do material e os declarados pelos estudantes. Considera-se que os componentes propostos pelas ferramentas de análise epistêmica, mediacional e cognitiva, se fizeram presente no material de maneira satisfatória. No que se refere a dimensão epistêmica, destaca-se os componentes linguagens, regras e argumentos com uma alta idoneidade, sendo que os dois primeiros também alcançaram uma alta idoneidade na dimensão cognitiva, o que indica uma produção, pelos estudantes, de significados fortemente relacionado com os significados pretendidos. $O$ único componente que apresentou uma baixa idoneidade foi análise e síntese, sendo que os demais componentes foram considerados com uma média idoneidade (situações-problema, relações, raciocínio lógico, leitura e interpretação).

Neste contexto, entende-se que os resultados alcançados com o material de estudos sobre Figuras Geométricas foram positivos, pois os estudantes conseguiram atingir grande parte dos 
significados pretendidos, com destaque, como já apresentado, para seus desempenhos na mobilização e articulação das definições e propriedades para resolver as situações-problema, como também, na diferenciação e no estabelecimento de relações entre figuras planas e espaciais. Porém, mais uma vez se destacam as dificuldades apresentadas nas atividades que envolviam argumentação e justificativas.

Os resultados apresentados neste artigo, evidenciam que os pressupostos do Enfoque Ontosemiótico do Conhecimento e da Instrução Matemática, mais especificamente, os componentes e indicadores da Idoneidade Didática, se revelam pertinentes e promissores, tanto para fundamentar 0 planejamento de um processo de ensino, no que se refere aos conhecimentos matemáticos envolvidos, as estratégias e recursos utilizados, como para a análise das aprendizagens, as interações produzidas a partir do mesmo, como também, possibilitando estabelecer critérios para seu aprimoramento.

\section{Referências}

ANDRADE, José Antônio Araújo. 0 ensino de geometria: uma análise das atuais tendências, tomando como referência as publicações nos Anais dos ENEM's. (Dissertação de Mestrado) Programa de Estudos Pós-Graduados em Educação. Universidade de São Francisco, Itatiba, 2004.

ANDRADE, Luísa Silva. Currículos de Matemática no Ensino Médio: um olhar sob s perspectiva do Enfoque Ontosemiótico do Conhecimento e a Instrução Matemática. Tese (Doutorado em Ensino de Ciências e Matemática) - Programa de Pós-Graduação em Ensino de Ciências e Matemática. Universidade Luterana do Brasil, Canoas. 2014.

BRASIL. Ministério da Educação e do Desporto. Secretaria de Educação Fundamental. Parâmetros Curriculares Nacionais: matemática, terceiro e quarto ciclos. Brasília: MEC/SEF, 1998. Disponível em: http://portal.mec.gov.br/seb/arquivos/pdf/matematica.pdf. Acesso em: 11 fev, 2014.

BRASIL, Ministério da Educação. Secretária de Educação Básica. Diretoria de Currículos e Educação Integral. Base Nacional Comum Curricular. Brasília: MEC, SEB, DICEI, 2018. Disponível em: http://basenacionalcomum.mec.gov.br/images/BNCC_EI_EF_110518_versaofinal_site.pdf. Acesso em: 21 jun, 2021.

CRESCENTI, Eliane Portalone. Os professores de Matemática e a Geometria: opiniões sobre a área e seu ensino. Tese (Doutorado em Educação) - Programa de Pós-Graduação em Educação.Universidade Federal de São Carlos. São Carlos, 2005. Disponivel em: https://repositorio.ufscar.br/bitstream/handle/ufscar/2380/TeseEPC.pdf?sequence=1. Acesso em: 29 jun, 2021.

GODINO, Juan Díaz. Indicadores de la idoneidade didáctica de processos de enseñanza y aprendizaje de las matemáticas. In: XIII CIAEM - IACME. Anais. Recife, 2011. Disponível em: http://www.ugr.es/ jgodino/eos/jdgodino_indicadores_idoneidad.pdf. Acesso em: 10 jun, 2021.

GODINO, Juan Díaz. Origen y aportaciones de la perspectiva ontosemiótica de investigación en Didáctica de la Matemática. In A. Estepa, A. Contreras, J. Deulofeu, M. C. Penalva, F. J. García y L. Ordóñez (Eds.), Investigación en Educación Matemática XVI. p. 49 - 68. Jaén: SEIEM, 2012. Diponível em: http://www.ugr.es/ jgodino/eos/origen_EOS_Baeza_2012.pdf. Acesso em: 11 jun, 2021 
GODINO, Juan Díaz. Indicadores de la idoneidad didáctica de procesos de enseñanza y aprendizaje de las matemáticas. Cuadernos de Investigación y Formación en Educación Matemática. $n^{011}$, p. 111-132, 2013. Disponível em http://revistas.ucr.ac.cr/index.php/cifem/article/viewFile/14720/13965. Acesso em: 19 mar, 2021.

GODINO, Juan Diaz; BATANERO, Carmen.; FONT, Vicenç. Um enfoque onto-semiótico do conhecimento e a instrução matemática. Acta Scientiae - Revista de Ensino de Ciências e Matemática, Canoas, v. 10, n.2, jul./dez., 2008. p. 07- 37. Disponível em:

http://www.periodicos.ulbra.br/index.php/acta/article/view/62. Acesso em 30 mar, 2021.

GODINO, Juan Díaz; RIVAS, Hernán; ARTEAGA, Pedro. Inferencia de indicadores de idoneidad didáctica a partir de orientaciones curriculares. Práxis Educativa, Ponta Grossa, v. 7, n. 2, jul./dez. p. 331-354. 2012 Disponível em: <http://www.revistas2.uepg.br/index.php/praxiseducativa>. Acesso em: 06 jun, 2021.

GODINO, Juan Diaz.; BENCOMO, Delisa.; FONT, Vicenç.; WILHELMI, Miguel R. Análisis y valoración de la idoneidad didáctica de procesos de estudio de las matemáticas. Paradigma, V.XXVII, n 2, p. 221-252, 2006. Disponível em: http://www.ugr.es/ jgodino/funcionessemioticas/idoneidad-didactica.pdf. Acesso em: 26 mar, 2015.

GODINO, Juan Diaz.; BATANERO, Carmen.; CONTRERAS, Ángel.; ESTEPA, Antonio Castro.; LACASTA, Eduardo.; WILHELMI, Miguel R. La ingeniería didáctica como investigación basada en el diseño. Versión ampliada en español de la comunicación presentada en el CERME 8 (Turquía, 2013) con el título, "Didactic engineering as design-based research in mathematics education", 2013. Disponível em: http://www.ugr.es/ jgodino/eos/JDGodino\%20et\%20al_2013\%20Ingenieria\%20didactica.pdf . Acesso em: 6 jun, 2021.

GODINO, Juan Diaz; BATANERO, Carmen; BURGOS, María; GEA, María M. Una perspectiva ontosemiótica de los problemas y métodos deinvestigación en educación matemática. Revemop, Ouro Preto, Brasil, v.3, n.202107, p. 1-30, 2021. DOI: https://doi.org/10.33532/revemop.e202107

GODINO, Juan Diaz. De la ingeniería a la idoneidad didáctica en educación matemática. Revemop, Ouro Preto, Brasil, v.3, n.202129, p. 1-26, 2021. DOI: https://doi.org/10.33532/revemop.e202129

LEMOS, Andrielly Viana. Estudos de recuperação no ensino fundamental: uma investigação no âmbito da geometria sob a perspectiva do enfoque ontossemiótico do conhecimento e da instrução matemática. Tese - Programa de Pós-Graduação em Ensino de Ciências e Matemática. Universidade Luterana do Brasil, Canoas, 2017.

LEMOS, Andrielly Viana.; KAIBER, Carmen Teresa. Estudos de Recuperação: uma proposta para a Geometria dos anos finais do Ensino Fundamental sob a perspectiva do Enfoque Ontossemiótico In: VII Congresso Internacional de Ensino da Matemática - CIEM, 2017, Canoas. Anais do VII CIEM. Canoas: ULBRA, 2017.

LORENZATO, Sergio. Por que não ensinar Geometria? Educação Matemática em revista, v. $3, n^{0} 4$, p. 3-13, 1995.

PAVANELLO, Regina Maria. O abandono do ensino da Geometria no Brasil: causas e consequências. Zetetiké. Campinas, SP. Ano I, n 1, p.7-17, 1993. 


\section{revemop}

PIRES, Célia Maria Carolino. Currículos de Matemática: Da Organização Linear à Idéia de Rede. São Paulo: FTD, 2000. 